\title{
Children and the Child Welfare System: Problems, Interventions, and Lessons from Around the World
}

\author{
Jarosław Przeperski ${ }^{1}$ (1) Samuel A. Owusu ${ }^{1}$
}

Accepted: 16 January 2021 / Published online: 30 January 2021

(c) The Author(s) 2021

\begin{abstract}
Securing the welfare of children and the family is an integral part of social work. Modern society has experienced enormous changes that present both opportunities and challenges to the practice of social work to protect the welfare of children. It is thus essential that we understand the experiences of social work practitioners in different parts of the world in order to adapt practice to the changing times. To help achieve this, we present a collection of papers from around the world that presents findings on various aspects of social work research and practice involving children and the potential for improved service delivery.
\end{abstract}

Keywords Child welfare $\cdot$ Child protection $\cdot$ Social work intervention $\cdot$ Youth

The protection of children's welfare in many parts of the world involve different institutions and professionals ranging from social workers to the police, courts, schools, health centers, among others. In the course of their duties, some form of collaboration to varying degrees occur between these institutions and professionals in order to secure the welfare of children (Lalayants, 2008).

The child welfare system and social work particularly, has been observed to have undergone complex changes from its inception till now (Bamford, 2015; McNutt, 2013; Mendes, 2005; Stuart, 2013). Historically, the family and the local community were in many societies, solely responsible for a child's well-being. When in crisis, the family including the wider extended family, was primarily responsible for supporting the child and solving their problems.

In response to wider changes in contemporary society, the child welfare system has increased the involvement of aid institutions protecting the welfare of children while reducing the role of the family. The family as a unit has also undergone changes, from the involvement of a broader network of relatives and the local community to the dominance of the nuclear family. Family ties have been weakened in many societies and the way the family unit functions has changed.

Jarosław Przeperski

jprzeperski@umk.pl

1 Centre for Family Research, Nicolaus Copernicus University, ul. Lwowska 1, 87-100 Toruń, Poland
Many children experience problems that often exceed the capacity of help available to these nuclear families. This has made it necessary to involve professional institutions (education, health, etc.) to aid in other areas outside of their core mandates to ensure children are secure, healthy, fed, and entertained and also to help families regain their own strength.

Although certain challenges to child welfare have persisted over time, children in contemporary times face some threats to their welfare unique to the times. Advancement in technology on one hand presents novel problems such as internet-use addictions and extensive means of child exploitation whiles on the other hand, these advancements in technology also provide opportunities to reach more clients effectively, gather data for analysis, and monitor and assess the performance of workers as well as the effectiveness of services. Modern ICT tools (such as online platforms and mobile applications) provide more flexibility in engagement between social workers and clients and the frequency of such meetings or engagements. However, an uncritical over-reliance on these tools presents other problems. Some social workers may be prone to avoid difficult situations involving uncooperative or violent families (Cooper, 2005) and an over-reliance on online meetings may worsened such cases, leaving vulnerable children unprotected.

All around the world, differences exist in the degree of exposure and the severity of problems facing children based on their age group (infants, toddlers, teens, and, youth), 
gender, geography, economic background, and culture. For instance, among the genders, differences exist in the probability of falling victim to child sexual abuse (Wellman, 1993) and the consequences of such victimization (Asscher, Van der Put, \& Stams, 2015). Children from poor families are more at risk of being involved with the welfare system in certain countries (Fong, 2017) while poor and developing countries lack some resources needed to support children and families compared to more developed and richer countries. In addition, cultural attitudes towards parenting in different parts of the world may exacerbate the problems of child neglect, corporal punishment, and other forms of abuse.

To ensure that social workers are better equipped to deal with the daunting task of protecting the welfare of children, reforms have been proposed which are aimed at improving on the knowledge and skills of social workers, instituting standards of practice based on data, striving for continuous excellence in organizations (Cahalane, 2013) among others. The social work interventions aimed at improving the welfare of children of any given society can be affected by political, cultural, and socio-economic factors and this needs to be understood and addressed during the design, implementation, and assessment stages of interventions. Reisch and Jani (2012) describe how politics affect the development of social programs at the macro and micro levels, workplace decision-making processes, and resource allocation for agencies and clients.

With the aim of understanding the various challenges facing social work and the child welfare system around the world and the existing opportunities to address them, several papers on varying topics related to child welfare have been collated into this special issue. The contributors come from Asia, Africa, North America, and Europe and present the results of research into different areas affecting child welfare, child welfare workers and institutions, and interventions. Many lessons can be learnt from understanding the problems facing children and their families from around the world, the services and interventions instituted to combat such problems, the state of mind of children and their relationships with others, and the potentials of modern tools to improve service delivery in the child welfare sector.

In the special issue, Filippelli, Fallon, Lwin and Gantous (2021) present the paper, "Infants and Toddlers Investigated by The Child Welfare System: Exploring the Decision to Provide Ongoing Child Welfare Services". Following the concerns of limited research into decision-making process of young children involved in the welfare system, the authors aimed to contribute to the literature on cases of maltreatment of young children and decisions to address them. The authors sought to answer the questions of the character of investigations of alleged child maltreatment, what factors influence decisions to recommend welfare service provision, and what differences may exist between cases involving infants and toddlers. After reviewing data on investigations into suspected cases of child maltreatment in Canada, it was determined that assessment by welfare workers and the mental health of caregivers are important indicators of decisions to transfer cases for further services. For cases involving infants, results indicate caregiver characteristics and household income are unique factors influencing decision-making while in toddler-involved cases, the toddler and the caregiver characteristics are factors that affect decisions.

Van Dam, Heijmans, and Stams (2021) aimed to determine the long-term effect of the intervention program, Youth Initiated Mentoring (YIM) organized in the Netherlands. They sought to find out how the mentors and the youth mentees were doing several months or years after the program and their impression of the whole program. In the paper "Youth Initiated Mentoring in Social Work: Sustainable Solution for Youth with Complex Needs?", they show some findings on the present situation of mentees, the quality and trajectory of mentor-mentee relationships, and the level of support from social workers. Results indicate a sustained relationship between majority of the mentors and mentees and a reduction in the likelihood of out-of-home placement among other long-term benefits. The authors offer some recommendations for future research into Youth Initiated Mentoring.

Mackrill and Svendsen (2021) in the paper, "Implementing Routine Outcome Monitoring in Statutory Children's Services" highlights the outcome of a 2-year long study on the effect of implementing a feedback-informed approach to family service provision in Denmark. In the study, they sought to understand how the feedback informed approach assisted in protecting children and families and what gaps exist in the service delivery chain. This involved analyzing by means of a constructivist grounded theory approach, anonymized data derived from field notes and interviews of various stakeholders. They report that the feedback-oriented approach helped service workers to follow legal directives especially in areas of assessment, care planning and followup, as well as in their approach to interviewing children. On the other hand, they assert that this approach to service delivery fails to emphasize attention to risk especially within families and the rights of clients to legal advice and recourse, among other issues. They offer some recommendations to address some of the identified challenges.

In order to understand the perceptions of the youth about older people with regards to healthcare and social help so that resources to address any existing negative stereotypes can be identified, Kanios (2021) surveyed 1084 schoolgoing young people in Poland. Findings of this survey are presented in the paper titled "Beliefs of Secondary School Youth and Higher Education Students About Elderly Persons: A Comparative Survey". Results show varied beliefs 
about older people regarding healthcare and social help among Secondary School Youth and Higher Education Students. Most of the respondents from both groups held no stereotypical views of older people. Students in higher education especially were found to maintain a more mature outlook on older people. Kanios concludes the paper with some recommendations of educational interest to combat existing negative stereotypes of older people.

Frimpong-Manso (2021) aimed to understand the views of social workers in Ghana on the benefits of intervention programs that strengthen families and to identify any existing barriers to their successful implementation in his paper, "Family Support Services in The Context of Child Care Reform: Perspectives of Ghanaian Social Workers". Qualitative data derived from interviews with social workers point to some benefits of the existing family support services such as capacity building and wellbeing promotion of the families. Some identified challenges to success include inadequate funding and poor interagency cooperation.

Odrowąż-Coates and Kostrzewska (2021) from Poland present an analysis of the indicators of successful and fulfilling teenage motherhood in their paper titled "A Retrospective on Teenage Pregnancy in Poland. Focusing on Empowerment and Support Variables to Challenge Stereotyping in the Context of Social Work". With the aim of showcasing positive cases of teenage motherhood as a means of empowerment and a way to tackle stereotypes in Poland, the authors utilized data from interviews and field practice notes involving teenage mothers and family court curators. Findings from this study show these teenage mothers to be empowered, independent, persevering, and with agency. Resources available through social work interventions and other support systems are also highlighted. The authors emphasize the need to show the positive life experiences of teenage mothers and the social work programs that contribute towards that in order to dispel existing stereotypes.

Abu Bakar Ah et al. (2021) in their paper, "Material Deprivation Status of Malaysian Children from Low-Income Families" relied on data from a self-reported survey of 360 poor children in Malaysia to determine their level of material deprivation. Results indicate a low level of material deprivation among poor Malaysian children. The authors include some recommendations to improve on the well-being of children in Malaysia.

With the hypothesis that the quality and quantity of placement of children with their kin depend on social workers, managers, and some organizational factors, Rasmussen and Jæger (2021) present a case study of social workers and their field practices related to kinship care in Denmark. Their paper, "The Emotional and Other Barriers to Kinship Care in Denmark: A case study in two Danish municipalities" contains analysis of the findings of their study. Through a mixed method approach of analyzing documents, interviews, observations, and dialogue meetings, data on placement into kinship care in two municipalities in Denmark were gathered. Among all the cases selected for the study, they reported a reasonable level of satisfaction among all parties involved. However, the authors indicate a hesitation among social workers to enter emotionally-charged familial situations which affects their decisions on kinship placement. The paper also points to the non-involvement of families in a systematic manner in placement decisions as another factor that affects placement decisions.

Grządzielewska (2021) from Poland, reviews how machine-learning can be applied as a tool to predict burnout among social work employees in the paper, "Using Machine Learning in Burnout Prediction: A Survey". The ability to analyze and interpret large amount of data makes the tools of machine learning very useful. The paper attempts to compare traditional and newer methods of predictive modeling and discusses how different variables affect the choice of appropriate methodologies. It is discussed in this paper how machine-learning algorithms can be incorporated into a burnout monitoring system to create new models of burnout, identify the potential for burnout among new recruits and existing employees, and design appropriate interventions. The author recommends further attention by social work researchers in the study of burnout.

We acknowledge the contributions of the various authors to making this special issue possible by sharing their perspectives on child welfare service delivery.

\section{Compliance with Ethical standards}

Conflict of interest The authors declare no conflict of interest.

Open Access This article is licensed under a Creative Commons Attribution 4.0 International License, which permits use, sharing, adaptation, distribution and reproduction in any medium or format, as long as you give appropriate credit to the original author(s) and the source, provide a link to the Creative Commons licence, and indicate if changes were made. The images or other third party material in this article are included in the article's Creative Commons licence, unless indicated otherwise in a credit line to the material. If material is not included in the article's Creative Commons licence and your intended use is not permitted by statutory regulation or exceeds the permitted use, you will need to obtain permission directly from the copyright holder. To view a copy of this licence, visit http://creativecommons.org/licenses/by/4.0/.

\section{References}

Abu Bakar Ah, S. H., Rezaul Islam, M., Sulaiman, S., et al. (2021). Material deprivation status of Malaysian children from lowincome families. Child and Adolescent Social Work Journal. https ://doi.org/10.1007/s10560-020-00732-x. 
Asscher, J. J., Van der Put, C. E., \& Stams, G. J. (2015). Gender differences in the impact of abuse and neglect victimization on adolescent offending behavior. Journal of Family Violence, 30, 215-225. https://doi.org/10.1007/s10896-014-9668-4.

Bamford, T. (2015). A contemporary history of social work: Learning from the past. Bristol: Policy Press.

Cahalane, H. (2013). Contemporary issues in child welfare practice. New York, NY: Springer.

Cooper, A. (2005). Surface and depth in the Victoria Climbie Inquiry report. Child and Family Social Work, 10(1), 1-9. https://doi.org /10.1111/j.1365-2206.2005.00350.x.

Filippelli, J., Fallon, B., Lwin, K., \& Gantous, A. (2021). Infants and toddlers investigated by the child welfare system: Exploring the decision to provide ongoing child welfare services. Child and Adolescent Social Work Journal, 11, 1-15.

Fong, K. (2017). Child welfare involvement and contexts of poverty: The role of parental adversities, social networks, and social services. Children and Youth Services Review, 72, 5-13. https://doi. org/10.1016/j.childyouth.2016.10.011.

Frimpong-Manso, K. (2021). Family support services in the context of child care reform: Perspectives of Ghanaian social workers. Child and Adolescent Social Work Journal. https://doi.org/10.1007/ s10560-020-00729-6.

Grządzielewska, M. (2021). Using machine learning in burnout prediction: A survey. Child and Adolescent Social Work Journal. https ://doi.org/10.1007/s10560-020-00733-w.

Kanios, A. (2021). Beliefs of secondary school youth and higher education students about elderly persons: A comparative survey. Child and Adolescent Social Work Journal. https://doi.org/10.1007/ s10560-020-00727-8.

Lalayants, M. (2008). Interagency collaboration approach to service delivery in child abuse and neglect: perceptions of professionals. International Journal of Interdisciplinary Social Sciences, 3, 225-336.

Mackrill, T., \& Svendsen, I. L. (2021). Implementing routine outcome monitoring in statutory children's services. Child and Adolescent Social Work Journal. https://doi.org/10.1007/s10560-020-00734 $-9$.
McNutt, J. (2013). Social work practice: History and evolution. Encyclopedia of Social Work. Retrieved January 11, 2021, from https ://oxfordre.com/socialwork/view/10.1093/acrefore/9780199975 839.001.0001/acrefore-9780199975839-e-620.

Mendes, P. (2005). The history of social work in Australia: A critical literature review. Australian Social Work, 58(2), 121-131. https ://doi.org/10.1111/j.1447-0748.2005.00197.x.

Odrowąż-Coates, A., \& Kostrzewska, D. (2021). A retrospective on teenage pregnancy in Poland: Focusing on empowerment and support variables to challenge stereotyping in the context of social work. Child and Adolescent Social Work Journal. https://doi. org/10.1007/s10560-020-00735.

Rasmussen, B. M., \& Jæger, S. (2021). The emotional and other barriers to kinship care in Denmark: A case study in two Danish municipalities. Child and Adolescent Social Work Journal.

Reisch, M., \& Jani, J. S. (2012). The new politics of social work practice: Understanding context to promote change. British Journal of Social Work, 42(6), 1132-1150. https://doi.org/10.1093/bjsw/ bcs072.

Stuart, P. (2019). Social work profession: History. Encyclopedia of Social Work. Retrieved January 11, 2021, from https:// oxfordre.com/socialwork/view/10.1093/acrefore/9780199975 839.001.0001/acrefore-9780199975839-e-623.

van Dam, L., Heijmans, L., \& Stams, G. J. (2021). Youth initiated mentoring in social work: Sustainable solution for youth with complex needs? Child and Adolescent Social Work Journal. https://doi. org/10.1007/s10560-020-00730-z.

Wellman, M. M. (1993). Child sexual abuse and gender differences: Attitudes and prevalence. Child Abuse \& Neglect, 17(4), 539-547. https://doi.org/10.1016/0145-2134(93)90028-4.

Publisher's Note Springer Nature remains neutral with regard to jurisdictional claims in published maps and institutional affiliations. 